\title{
A Conceptual Framework of the Adoption and Practice of Environmental Actions in Households
}

\author{
Anna Scott ${ }^{1, *}$, Caroline Oates ${ }^{2, \dagger}$ and William Young ${ }^{3, \dagger}$
}

1 Keep Britain Tidy, Development House, 56-64 Leonard Street, London EC2A 4LT, UK

2 Sheffield University Management School, University of Sheffield, Conduit Road, Sheffield S10 1FL, UK; E-Mail: c.j.oates@sheffield.ac.uk

3 Sustainability Research Institute, School of Earth and Environment, University of Leeds, Woodhouse Lane, Leeds LS2 9JT, UK; E-Mail: c.w.young@leeds.ac.uk

$\dagger$ These authors contributed equally to this work.

* Author to whom correspondence should be addressed; E-Mail: anna.scott@keepbritaintidy.org; Tel.: +44-1942-612621.

Academic Editor: Marc A. Rosen

Received: 25 February 2015 / Accepted: 7 April 2015 / Published: 12 May 2015

\begin{abstract}
Securing public participation in environmental actions such as recycling, energy conservation measures and green consumerism is a means of progressing towards sustainable consumption. Participation in environmental actions (EAs) has typically been studied from the individual perspective, thus largely ignoring the social context of the household which may undermine effective behaviour change and green marketing strategies. This paper advances understanding of the adoption and practice of EAs from the household perspective by drawing together the limited and fragmented work which has examined EA participation from the household perspective, and integrating it with two relevant literatures - the household decision making literature and the literature which has examined EA participation from the individual perspective. The literatures are drawn together into a framework covering household member involvement in EA adoption and practice, the decision making process leading to EA adoption, decision making strategies and communication within the household, the maintenance of repetitive EAs, the factors influencing household member involvement including activity types and situational, household and individual characteristics, and how the individual characteristic of relative interest is shaped. We make a theoretical contribution by presenting a holistic understanding of the adoption and practice of EAs in households, which was previously lacking from the
\end{abstract}


EA participation literature. By highlighting the elements of the conceptual framework that require further investigation, the authors also set out an agenda for research into EA participation from the household perspective.

Keywords: environmental actions; households; conceptual framework; literature review

\section{Introduction}

Humanity's Ecological Footprint (a measure of human impact upon the planet's natural resources) now exceeds the planet's ability to regenerate renewable resources and absorb $\mathrm{CO}_{2}$ waste by $50 \%$ [1]. In response, as a means of progress towards environmentally sustainable levels of consumption in more economically developed countries, government and non-governmental organisations advocate public participation in environmental actions (EAs) in the home and everyday life, such as recycling, energy conservation measures and green consumerism.

The rise of the sustainable consumption agenda has been accompanied by the proliferation of research into EA participation. Two main bodies of knowledge have emerged from this voluminous literature. The "determinants of behaviour" body of knowledge represents an understanding of the broad range of internal and external factors which may influence behaviour and interact with each other, categorised for example by Stern [2] as attitudinal factors including general environmentalist disposition and behaviour-specific norms and beliefs, personal capabilities including financial resources and behaviour-specific knowledge and skills, contextual factors including appropriate infrastructure and social norms, and habit and routine. The "behaviour change" body of knowledge represents an understanding of how to most effectively bring about voluntary behaviour change. Traditionally, research that has contributed to these two bodies of knowledge has used the individual as the unit of analysis, thus ignoring that the adoption and practice of EAs actually takes place in, and is shaped by, the social context of the household. While some research programs have focused on households, they have been concerned with developing socially and technologically innovative scenarios for sustainable household consumption [3-5], rather than relying on efficiency-based EAs. The work of Shove [6,7] has examined how practices pertaining to environmentally significant consumption are shaped within everyday life, but a growing number of studies have explicitly taken the household as the unit of analysis and begun to explore how individuals within households interact with respect to the adoption and practice of EAs [3-5,8-17]. For example, as highlighted above, one factor which is deemed to influence behaviour is social norms. While some studies have referred to the importance of the influence of household members within discussion of social norms, e.g., Ewing [18], Kok and Siero [19], this issue is more typically overlooked. However, household-focused research has identified "the influence of gatekeepers acting as social catalysts and driving the acceptance of pro-environmental behaviour" within the household [20] (p. 321). Similarly, taking the individual as the unit of analysis has also overlooked the division of responsibility within the household for EA adoption and practice. However, household-focused research has highlighted a relationship between gender, the domestic division of labour and involvement in EA adoption and practice [5,9-11,15,17,21,22]. Thus, as widespread adoption of EAs by the public remains a considerable and pressing challenge for policy makers, a greater 
understanding of the household as the social unit represents an informative avenue for behaviour change and green marketing strategies [20].

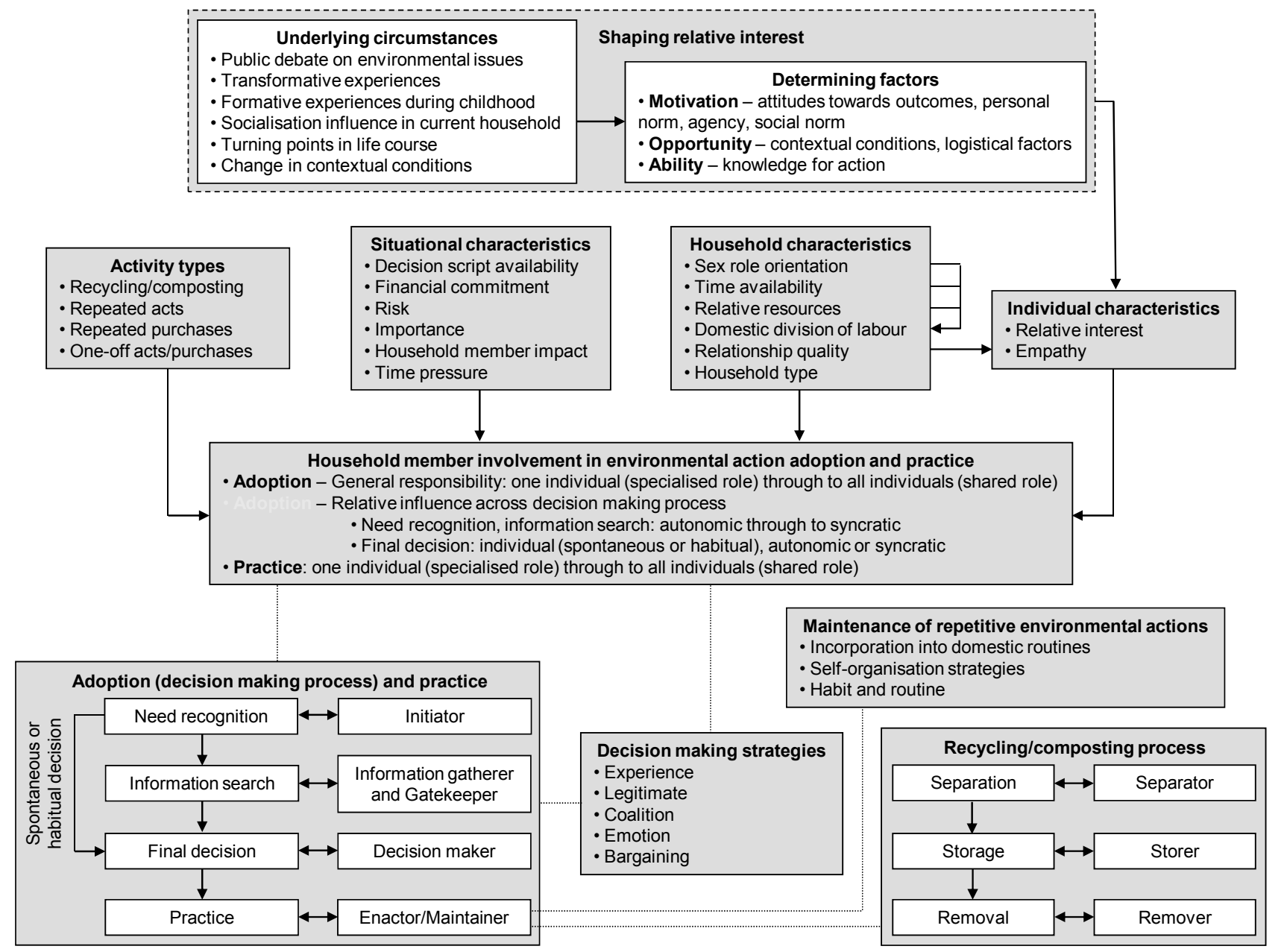

Figure 1. A conceptual framework of the adoption and practice of lone environmental actions in households.

As a first step to advancing holistic understanding of EA participation from the household perspective, we present a conceptual framework of the adoption and practice of EAs in households derived from the literature (Figure 1). This framework brings together the largely unlinked work which has examined EA participation from the household perspective (the "household literature"), and integrates it with two other literatures of relevance. Firstly, the household decision making literature (the "HDM literature"), which has had limited application to the study of EA participation [9]. The framework is particularly informed by Lee's [23] model of family buying behaviour and Levy and Lee's [24] framework of family decision making. Secondly, the literature which has examined EA participation from the individual perspective (the "individual literature"), specifically the literature pertaining to the determinants of behaviour and the limited and fragmented work which has examined behaviour change in a natural setting (as opposed to in response to specific intervention strategies). The framework is focused on lone EAs (i.e., single EAs considered in isolation), but incorporates some commentary about patterns of adoption and practice across EA repertoires (i.e., the collection of EAs evident in the household). The framework recognises that while the adoption and practice of EAs may 
be underpinned by the conscious minimisation of environmental impact, EAs may also be driven by non-environmental motivations (e.g., saving money in the case of energy conservation measures) and may be more matters of habit as opposed to conscious behaviour. The framework is presented in Figure 1 with the following discussion structured around each component of the framework in turn, including relationships between components. As such, the discussion begins with "household member involvement in EA adoption and practice" (Section 2), followed by the related components of "adoption (decision making process) and practice" and "recycling/composting process" (Section 3) and "decision making strategies" (Section 4). The discussion then turns to "maintenance of repetitive environmental actions" (Section 5). This is followed by the examination of the four types of factors conceptualised as influencing household member involvement in EA adoption and practice, namely "activity types" (Section 6), "situational characteristics" (Section 7), "household characteristics" (Section 8) and "individual characteristics" (Section 9). Lastly, "shaping relative interest" is considered (Section 10), namely how this individual characteristic is shaped by determining factors (Section 10.1), which are in turn shaped by underlying circumstances (Section 10.2).

\section{Household Member Involvement in Environmental Adoption and Practice}

EA adoption refers to the decision making process leading to the practice of a one-off EA or the physical initiation of a repetitive EA. Household member involvement in EA adoption is considered initially at the level of general responsibility, as a spectrum from one individual being responsible for EA adoption in a specialised role through to all individuals being responsible in a shared role, as supported by studies within the household literature $[5,9,11,15]$. However, these studies have tended to highlight different ends of the spectrum in relation to different EAs, and there has been little discussion of the detailed nature of these different involvement distributions.

Relative influence (influence relative to the influence of other household members) across the decision making process is a central concept in the HDM literature, and therefore offers a starting point for exploring involvement in EA adoption at a second, more detailed level. Hence, there is a link between the "household member involvement in environmental action adoption and practice" component of the framework and "adoption (decision making process) and practice", represented by a dashed line in Figure 1. Direct influence represents actions by individuals that have an impact on the decision making process [25]. However, individuals may also have indirect influence whereby their preferences are indirectly taken into account by another household member [26].

Numerous studies within the HDM literature have characterised the need recognition, information search and final decision stages of the decision making process as autonomic (one individual has dominant influence in a specialised role) through to syncratic (individuals have equal influence in a shared role), e.g., Belch et al. [27], Belch and Willis [28], Martínez and Polo [29]. However, Kirchler et al.'s [30] broader characterisation of the final decision also incorporates indirect influence. As such, an individual decision is made independently of other household members and both types - spontaneous and habitual-bypass active information search. An autonomic decision represents one individual making the decision but with the preferences of other household members taken into account, while a syncratic decision refers to the household collectively making the decision, with both types involving the extended decision making process. 
EA practice refers to the actual exercise of a one-off EA or the maintenance of a repetitive EA. Involvement in EA practice is considered as a spectrum from one individual practicing the EA in a specialised role through to all individuals practicing the EA in a shared role. Involvement in EA practice has been touched upon by the individual literature, with reference to recycling falling to one household member, typically the female [31-34]. EA practice falling to one household member has also been reported by the household literature with EAs typically falling to the female including recycling [15,22] (however, evidence presented by Pettifor [17] challenges this notion, see the "household characteristics" section), the purchase of organic food [9], and routine-orientated energy conservation EAs [10,35]. EAs typically falling to the male include home composting $[9,11]$ and energy conservation EAs involving structural changes, e.g., installing insulation [10]. Furthermore, with respect to energy, Grønhøj and Thøgersen [12] identified that male householders took a greater interest in a feedback system displaying real time electricity consumption, and thus were more likely to be in control of electricity consumption in the household. Explanations of the gendered nature of involvement in EA adoption and practice are discussed in the "household characteristics" section. Fewer studies within the household literature have identified the shared practice of EAs. Oates and McDonald [15] identified joint activity with respect to recycling adoption and practice but recognised that 'the term 'joint' could have a whole range of meanings from an occasional contribution to an equally shared activity" (p. 429).

A particular distribution of involvement in EA adoption associated with a particular distribution of involvement in EA practice can be regarded as one route to EA practice. Only the skeletal forms of different routes to EA practice have been outlined. For example, Oates and McDonald [15] identified combinations of recycling initiator and sustainer in households. Common combinations were: single initiator and single sustainer; joint initiator and joint sustainer; single initiator and joint sustainer; and joint initiator and single sustainer. Oates and McDonald [15] also reported a $61 \%$ level of continuity of recycling responsibility from initiation to sustaining. Where the role did change hands, a single initiator changing into jointly sustaining recycling was much more likely than the opposite scenario. Grønhøj [9] and Grønhøj and Ölander [11] recognised situations in which an EA is "started by one spouse, and subsequently accepted and adopted by the other" [9] (p. 500) as a socialisation influence from one adult to another. This, and socialisation influences from parent to child, and from child to parent will be discussed further in the "shaping relative interest" section.

\section{Adoption (Decision Making Process) and Practice, Recycling/Composting Process}

With respect to EA adoption, the need recognition, information search and final decision stages of the decision making process, correspond to the roles of initiator, information gatherer and gatekeeper, and decision maker respectively [24]. The three stage decision making process is drawn from the HDM literature where it has been commonly utilised in relative influence studies in relation to frequently purchased goods, durable goods and other economic decisions, e.g., Belch, Belch, and Ceresino [27], Davis and Rigaux [36], Martínez and Polo [29]. The information search stage has two aspects — seeking information from external sources and retrieving internal information from memory, e.g., Davis and Rigaux [36], Olshavsky and Granbois [37].

Autonomic and syncratic decisions involve the extended decision making process whereas individual (spontaneous or habitual) decisions bypass active information search [30]. The individual literature 
indicates that the public rarely searches for information from external sources about EAs and thus generally gathers information passively (see the "shaping relative interest" section). This suggests that the relevance of the extended decision making process to EA adoption may be somewhat overstated. However, the conceptualisation of the decision making process employed represents a starting point for empirical investigation rather than an assumed depiction of reality [30]. Indeed, with respect to decision making processes associated with sustainable technologies (e.g., energy efficient appliances, green electricity tariffs, etc.), Oates et al. [38] documented the interplay between various types of decision criteria, while Young et al. [39] increased the complexity of this picture with the addition of other factors for the "greenest" consumers such as the time available for research and decision making. This highlights the likely complexity of the decision making process with respect to one-off acts/purchases, and households with the strongest environmental orientation. However, a different picture is evident with respect to repeated purchases, at least after the initial decision making process. As such, Thøgersen et al. [40] investigated how consumers make decisions about the purchase of milk when both organic milk and the conventional alterative are available. Rather than causing "green" consumers to deliberate more in the choice situation, the availability of a "green" alternative appears to make such consumers develop a new, simple heuristic that allows them to make their choice without additional time or effort compared to those purchasing the conventional alternative.

EA practice corresponds to the role of enactor in the case of a one-off EA, or the role of maintainer in the case of repetitive EAs. Despite the individual literature regarding recycling as a single act, recycling practice actually consists of a series of tasks constituting a process [15,21,41]. The three stages of separation, storage and removal correspond to the roles of separator, storer and remover respectively [41]. Hence, the dashed line linking EA practice and the role of enactor/maintainer and the "recycling/composting process" component of the framework in Figure 1.

\section{Decision Making Strategies}

The HDM literature contends that some degree of conflict is highly likely in the decision making process as individual preferences are unlikely to be uniform across the household, e.g., Lee and Collins [42], Wilkie et al. [43]. Indeed, it should not be assumed that household members have identical values in relation to EA participation [5]. The term "conflict" refers to explicit or implicit disagreement between household members on the rationale or outcome of a decision [44]. Lee and Collins [42] identified five decision making strategies that households may use in an attempt to resolve conflict and come to a joint decision (Table 1) by integrating strategies identified by Davis [45], Qualls and Jaffe [46], Sheth [47] and Spiro [48]. Thus, the link between the "decision making strategies" and the "household member involvement in environmental action adoption and practice" and "adoption (decision making process) and practice" components of the framework, as represented by dashed lines in Figure 1. 
Table 1. Household decision making strategies (after Lee and Collins [42]).

\begin{tabular}{cc}
\hline Decision Making Strategy & Definition \\
\hline Experience & $\begin{array}{c}\text { Using experience and knowledge as a source of } \\
\text { information that will influence the decision outcome }\end{array}$ \\
\hline Legitimate & $\begin{array}{c}\text { Emphasising a role stereotype in order to obtain influence } \\
\text { Two or more household members collude } \\
\text { in order to obtain a particular outcome }\end{array}$ \\
\hline Emotion & $\begin{array}{c}\text { A household member tries to persuade or dominate others } \\
\text { by using emotive appeals, crying, pouting and other } \\
\text { non-verbal techniques in order to achieve influence } \\
\text { A household member gives in one occasion in } \\
\text { return for getting their way on some other occasion }\end{array}$ \\
\hline
\end{tabular}

The entirety of Lee and Collins' [42] framework of decision making strategies to EA adoption has not yet been fully examined. However, Gentina and Muratore [16] recently identified bargaining, reasoning, persuasion and nagging as influence strategies used by teenagers with their mothers in relation to EAs, and linked their effectiveness to Carlson and Grossbart's [49] parental style scale. As such, parental styles with bilateral strategies (bargaining, reasoning) were the most effective with warmer (authoritative and permissive) mothers, while unilateral strategies (persuasion, nagging) were the least effective with cooler (authoritarian and neglecting) mothers. Grønhøj [9] also identified interpersonal influence (regarded as one household member bringing about a change in another household member's behaviour) through overt conflict-ridden discussions. However, conflict was often implicit and unspoken, and interpersonal influence through "peaceful" communicative acts was also evident [9,11], thus highlighting the need to explore both overt conflict-ridden and peaceful interpersonal influence processes.

Bound up within overt conflict-ridden and peaceful interpersonal influence processes is the wider issue of communication within the household about EAs. Grønhøj [9] noted that EAs which had become habit were not on the communication agenda. Communication was also usually negligible where only one individual had an interest in the EA, even when the more interested individual preferred a change in their spouse's behaviour. However, in some cases differences of opinion would sometimes prompt discussion. Discussions between parents and children were more frequently reported than discussions between spouses. In addition to parental style, frequency of communication was identified as a factor impacting on teenagers' influence on their mothers' engagement with EAs by Gentina and Muratore [16]. As such, although warmer mothers may be more receptive to attempts to influence them, this may be hindered by restrictions on the frequency of communication when mothers work.

Further to Grønhøj's [9] point about differences of opinion between spouses, Thørgersen and Grønhøj [35] presented evidence to suggest that men are more inclined than women to put explicit pressure on their spouse when they perceive she is less committed to saving electricity. Grønhøj and Ölander [11] found that although spouses' responses to issues relating to EAs did not greatly differ, spouses perceived the differences between themselves and their spouse to be great. Couples who did not engage in EAs were more inclined to perceive such a difference. This led Grønhøj and Ölander [11] to contend that perceived disagreement may be the result of a lack of communication within the household; as a result, "established habits and routines are never challenged if couples avoid talking about these issues" (pp. 230-231). Indeed, the success of intervention strategies such as real time feedback on electricity consumption and 
household diaries at inducing behaviour change are, in part, attributable to the stimulation of discussion between household members [12,50].

\section{Maintenance of Repetitive Environmental Actions}

Different factors influence the initiation of a repetitive EA and influence its persistence [5,51]. Studies which have specifically examined repetitive EA maintenance as opposed to generic participation in an EA point to the importance of the incorporation of EA practice into domestic routines, self-organisation strategies with respect to recycling, and habit and routine. Hence, the dashed line linking EA practice and the role of enactor/maintainer and the "maintenance of repetitive environmental actions" component of the framework in Figure 1.

Oates and McDonald [15,52] highlighted the incorporation of recycling tasks into domestic routines, and Pocock et al. [53] reported that 95\% of recyclers surveyed agreed that recycling is part of their regular household routine. Pettifor [17] formally tested this relationship and identified a significant association between recycling and domestic routines; however, she also argued that recycling does add to the domestic burden of the household rather than being an entirely benign activity. Given that the household literature indicates that sex role orientation and the domestic division of labour influence involvement in the adoption and practice of EAs other than recycling/composting, and the repetitive nature of repeated acts and repeated purchases, it is reasonable to suggest that the practice of these EA types may also be incorporated into domestic routines.

Self-organisation strategies refer to the separation of recyclables into containers and the combining of recycling tasks with other activities [54]. Such strategies have been identified as making recycling easier, and are associated positively with recycling behaviour, "unconscious competence" with respect to recycling and more favourable attitudes towards recycling [53-55]. Conversely, household disorganisation is a barrier to recycling as much as possible [53]. Despite the apparent importance of self-organisation in recycling maintenance, however, the role of such strategies remains underrepresented in recycling behaviour research [54].

Much environmentally significant consumption, particularly the consumption of energy and water "is occasioned by the routine accomplishment of what people taken [sic] to be normal and ordinary practice" [7] (p. 294). As Burgess [56] (p. 278) notes "many different kinds of social practices and behaviours are learned in childhood and subsequently enacted without any kind of conscious thought or reasoning". Therefore, it is important to recognise the role of parental influence in shaping routine and habitual behaviour [6] and thus determining what is seen as normal practice (whether this represents participation or non-participation in a repetitive EA), an issue which will be returned to in the "shaping relative interest" section.

Various models of habitual behaviour [57-59] highlight the discursive nature of change which is facilitated by social interaction [60]. Indeed, Global Action Plan's EcoTeams program, which is one of the most successful behaviour change initiatives in terms of quantified environmental savings (e.g., [61]) revolves around discursive processes and social interaction in a group setting [56,62]. However, how habitual behaviour is changed in the specific group environment of the household has not been explored.

The discussion will now turn to the four categories of factors conceptualised as influencing household member involvement in EA adoption and practice - activity types, situational characteristics, household 
characteristics and individual characteristics. The latter three categories have been drawn from the HDM literature, particularly four frameworks of family decision making [23,24,30,63], although such support is not EA-related. The inclusion of some factors is also supported by the household literature, although in some cases this is from a limited number of studies.

\section{Activity Types}

EAs are typically classified by sector (e.g., waste management, energy conservation, transport behaviour, water conservation and green consumerism). However, Gilg and Barr [64] provided empirical evidence from factor analysis that EAs are more usefully conceptualised by activity type than by sector. As such, there are four environmental activity types which parallel those used by Defra [65] — recycling/composting, repeated acts (e.g., turning lights off in unused rooms), repeated purchases (e.g., buying "environmentally friendly" cleaning products), and one-off acts/purchases (e.g., buying energy efficient appliances).

The following section outlines a number of situational characteristics which may influence involvement in EA adoption, specifically the nature of the final decision. While the relevant situational characteristics are likely to vary according to the EA and household in question, work within the household literature suggests that the activity type may implicitly determine the nature of the final decision. Specifically, "source-separation and composting in households with more than one member requires not only agreement about the decision but also enduring, action-oriented co-operation between the members of the family" [5] (p. 48). Thus, this perspective suggests that recycling/composting may be intrinsically associated with a syncratic decision. However, the identification of single initiators and single sustainers of recycling by Oates and McDonald [15] would question the prerequisite of a joint decision.

\section{Situational Characteristics}

The HDM literature and issues within the individual literature suggest that a variety of situational characteristics may influence involvement in EA adoption, specifically the nature of the final decision. Within the HDM literature, Kirchler et al. [30] refers to three factors which are relevant to EAs:

- Decision script availability, which refers to the cognitive complexity of EA adoption. The more familiar the decision and the less information needed, the more likely it is that cognitive scripts are available and therefore the less likelihood of a syncratic decision. Thus, if EA adoption relates to an EA which an individual has experience of or an EA which involves a simple choice as opposed to choosing between a complicated set of alternatives, then an individual decision may be the norm.

- Financial commitment. EAs which involve high monetary outlay may be associated with a syncratic decision due to the commitment of shared finances. This may apply to the range of repeated purchases and one-off acts/purchases given the subjective nature of cost (see the "shaping relative interest" section).

- Household member impact. The more household members who are affected by an EA, the greater the likelihood of a syncratic decision. 
Sheth [47] refers to three further situational factors:

- Risk. The greater the perceived risk of making a wrong decision, the greater the likelihood of a syncratic decision. Repeated purchases and one-off acts/purchases in particular may be associated with high levels of risk due to perceptions of such choices as expensive, unattractive and low quality $[66,67]$.

- Importance. The greater the importance of a decision, the greater the likelihood of a syncratic decision. Purchases traditionally recognised as important include appliances and cars (Sheth, 1974) [50] which suggests that buying an energy efficient appliance and a fuel efficient car may be associated with a syncratic decision.

- Time pressure. The more a household is pressed for time, the less the likelihood of a syncratic decision.

\section{Household Characteristics}

Household characteristics include sex role orientation, the domestic division of labour, household type, and interpersonal relationship quality. The HDM and household literatures suggest that role orientation includes involvement in EA adoption (specifically the nature of the final decision) and practice. Within the HDM literature, [47] noted that if specific roles have been implicitly or explicitly assigned to individuals then this tends to bring about greater autonomy and less syncratic decision making. The HDM and household literatures point to the relevance of two inter-related perspectives on role orientation - sex-role orientation and the domestic division of labour.

With respect to sex role orientation, couples can be identified along a continuum from traditional to modern modern [68]. In traditional couples, there is a clear distinction between male and female type roles with the male spouse tending to dominate the decision making process. Modern couples, on the other hand, have a more democratic structure with the male and female spouse making syncratic decisions and a blurring between male and female type roles. Indeed, Qualls [68] reported a relatively strong relationship between sex role orientation and the relative influence of husbands and wives.

There is much evidence in the household literature linking gender, the domestic division of labour and involvement in EA adoption and practice. The explanation of EAs such as [15,22], the purchase of organic food [9], and routine-orientated energy conservation EAs [10,35] typically falling to the female, while home composting $[9,11]$ and energy conservation EAs involving structural changes, e.g., installing insulation [10] typically falling to the male, lies in the "traditional inside-outside' distribution of household chores" [11] (p. 227) whereby females are assigned roles within the home such as childcare and housework, and males are assigned roles outside the home such as gardening and financial arrangements. Thus, this explanation refers to an enactment of gender in line with a more traditional sex role orientation [15,17]. Alternatively, Dickinson [21] and Pettifor [17] indicated that the distribution of involvement in EA adoption and practice relates more to the domestic division of labour rather than to gender itself [21], with the domestic division of labour decided by the availability of household members and the amount of work to be done (time availability theory) or the product of bargaining between partners conditional on their relative economic resources (relative resources theory) $[15,17]$.

The spectrum of household member involvement in the adoption and practice of a lone EA may sit within a similar spectrum of general responsibility for EA adoption and practice across the EA repertoire. At one end, one individual is generally responsible for EA adoption and practice in a specialised role 
(the "household EA officer"), while at the other end all individuals are generally responsible for EA adoption and practice in a shared role. This spectrum has been drawn from the HDM literature, with the household EA officer paralleling the "family financial officer"- - the spouse with the main responsibility for managing family finances with respect to decision making and [69]. This spectrum has not been squarely examined by the household literature, although the studies outlined in the previous paragraph also support the inter-related issues of sex role orientation and the domestic division of labour influencing general responsibility for EA adoption and practice across the EA repertoire. Carlsson-Kanyama and Lindén [10] and Grønhøj and Ölander's [11] findings suggest that where all individuals are generally responsible for EA adoption and practice across the EA repertoire in a shared role, this may take the form of male and female spouses taking responsibility for the adoption and practice of different EAs, as opposed to spouses sharing responsibility for each EA.

The HDM literature focuses firmly on decision making in couples and families with almost no reference to decision making in other household types such as shared households, although many of the concepts relating to family decision making should also apply to other household types [43]. Nonetheless, it would also seem likely that household type would have some bearing on involvement in EA adoption and practice.

Kirchler et al. [30] notes that there is less likelihood of a syncratic decision if interpersonal relationship quality is poor. Furthermore, an individual's empathy towards another household member is likely to depend on relationship quality [30].

\section{Individual Characteristics}

Individual characteristics include relative interest and empathy. Within the HDM literature, relative interest refers to how important the outcome of a particular decision is to an individual, e.g., Blackwell et al. [70], Burns and Granbois [71]. Relative interest "has not been conceptualised clearly or integrated into the environmental behaviour literature" [72] (p. 1266). Thus, within the framework, relative interest refers to the level of importance a household member places on participating in a particular EA (interest relative to the interest of other household members). As such, relative interest is a preference regarding personal action rather than how favourable an individual is towards the EA in general (attitude) or a cognitive commitment to act (behaviour intention) [73].

The HDM literature suggests that relative interest influences involvement in EA adoption, specifically the nature of the final decision; the greater an individual's relative interest, the greater their relative influence in the decision, e.g., Corfman and Lehmann [74], Gupta et al. [63], Levy and Lee [24]. The household literature also broadly suggests that relative interest influences involvement in EA adoption and practice $[5,22]$.

Within the HDM literature, empathy represents the importance to an individual that the preferences of other household members are accounted for in the decision $[75,76]$. This concept has not been utilised in relation to EAs. Therefore here, empathy refers to how important it is to an individual that the preferences of other household members are accounted for in the adoption and practice of a particular EA. The HDM literature suggests that empathy influences the decision outcome, specifically that where relative interest in an EA differs, the decision outcome is likely to reflect the preference of the individual who is the object of other household members' empathy [71]. An individual is likely to value the 
preferences of other household members more highly when the ties between household members are stronger [30]. Hence, empathy may be influenced by the household characteristic of interpersonal relationship quality.

\section{Shaping Relative Interest}

According to the contemporary position of the determinants of behaviour body of knowledge, behaviour is influenced by a broad range of internal and external factors which may vary greatly across EAs and individuals, and interact with each other [2,60,77-79]. As the concept of relative interest has not been specifically utilised in relation to EAs, it is conceptualised that relative interest is shaped in the same manner as actual behaviour. The determining factors of relative interest which are organised under motivation, opportunity and ability are in turn shaped by various underlying circumstances.

\subsection{Determining Factors}

A modified version Ölander and Thørgersen's [80] motivation-ability-opportunity-behaviour model provides a means of organising the determining factors and conceptualising broadly how these factors interact. As such, an individual's relative interest is shaped by their motivation to participate in the EA as well as the opportunity and their ability to do so.

Rather than conceptualising motivation in terms of Fishbein and Ajzen's [81] theory of reasoned action or Schwartz's [82] norm-activation model of altruism as Ölander and Thørgersen [80] have done, motivation can be more simply conceptualised as four factors which represent internal reasons to participate in an EA:

- Attitudes towards the outcomes of the EA represents the individual's beliefs about what the EA achieves and their evaluations of those beliefs. Beliefs which are evaluated favourably represent motives for EA participation. EA participation may be underpinned by a number of different motives. Environmental motives can either be general (e.g., to save the environment) or EA specific (e.g., avoid filling up landfill sites in relation to recycling), e.g., Bagozzi and Dabholkar [83]. A desire to avoid waste (whether domestic waste, energy or water) may be distinct from a desire to reduce environmental impact [65]. Motives may be non-environmental such as saving money in relation to energy conservation EAs [67,84], and health benefits in relation to walking or cycling instead of using the car $[9,85]$. Finally, motives may also include intrinsic satisfaction, i.e., personal, internal contentment derived from participating in EAs [86].

- Non-self serving motives to participate in an EA may be felt as a personal norm (a feeling of moral obligation) to act [82] as demonstrated by Davies, Foxall, and Pallister [87], Hallin [88], Hunecke et al. [89] and Kaiser, Hübner, and Bogner [90].

- Agency refers to "people's belief in their own ability to bring about" [91] (p. 19) and also been termed response efficacy [77], locus of control [78,92], and perceived consumer effectiveness [93,94]. Agency is also a component of Peattie's [95] concept of confidence in relation to green consumerism EAs. Individuals with a greater sense of agency believe that their actions make a difference whereas those with a low sense of agency feel that their actions are insignificant and only those with more power can bring about change. Agency has been found to have a direct 
impact on behaviour, [94,96], and to moderate the relationship between environmental concern and EA participation $[93,97]$.

- Social norm, which has also been termed subjective [81,98], refers to social influence. Cialdini et al. [99] distinguished between the descriptive norm which refers to what is typical or normal behaviour, and the injunctive norm which refers to beliefs about what others regard as morally appropriate and inappropriate behaviour. Studies which have demonstrated the influence of social norm on behaviour include Oskamp et al. [100] (descriptive norm), Gamba and Oskamp [101] (descriptive and injunctive norm), and Davies, Foxall, and Pallister [87] (injunctive norm). Discussions of social norm tend not to specifically flag up the influence of household members. However, in relation to recycling, Kok and Siero [19] identified family members as the most important references within social norm with friends being less important. Ewing [18] reported that the expectations of household members were important in relation to the decision to participate in kerbside recycling and played an even greater role in relation to the proportion of waste recycled.

Ölander and Thørgersen [80] preferred to conceive of opportunity as an objective precondition for the EA but acknowledged its subjective nature. Here, opportunity refers to contextual conditions, which is more objective in nature and the logistics of the EA, which is more subjective in nature.

Contextual conditions include government regulations, legal and institutional, financial incentives and costs, technical/built environment capabilities and constraints and public policies to support behaviour [2]. Bulkeley, Watson and Hudson [1] highlight the important point of the complexity of implementing government policies and the governance of waste sites and activities. They point to multiple levels and institutional arrangements influencing waste disposal, which has led to a diversity of practice. With respect to recycling, contextual conditions may include pay-by-use mechanisms [2] and access to communal or doorstep recycling services. Indeed, studies examining the impact of contextual conditions on behaviour have commonly focused on the provision of kerbside recycling services, often reporting such access to be a dominant predictor of recycling, e.g., Barr [77], Berger [102], Best and Kneip [103], Derksen and Gartrell [104]. In terms of interaction between contextual conditions and environmental concern, environmental concern influences behaviour primarily under conditions connected with low cost (in its broadest sense), i.e., where it is easier for individuals to transform their attitudes into corresponding behaviour, according to the low-cost hypothesis [105]. In contrast, Guagnano et al. [106] attitude-behaviour-context model contends that there is no virtually link between attitudinal factors and behaviour when contextual factors are strongly negative (i.e., make the EA very difficult) or strongly positive (i.e., make the EA extremely easy). However, both models highlight the general position of the determinants of behaviour body of knowledge that there is concordance between attitudes towards, and participation in, a particular EA, unless favourable attitudes cannot be translated into action due to a lack of opportunity or ability.

Logistical factors include a range of factors which are frequently cited as a reason for EA non-participation, particularly recycling, and a reason for not recycling more. These factors represent perceptions rather than objective measures [66,77,91,107]: 
- Lack of time, e.g., Pocock et al. [53], Robinson and Read [108], Watts and Probert [109]. Time can refer to the time it takes to clean, separate and store recyclables and transport them to the final recycling facility, e.g., ENCAMS [110], Gamba and Oskamp [101], and time related to organising recycling routines [66].

- Lack of storage for recyclables, e.g., Defra [85], Hayward et al. [111], Pocock et al. [53], Watts and Probert [109]. Some surveys have found that "not having enough recyclables" is a reason for not recycling, e.g., McDonald and Oates [112], Perrin and Barton [113], Tucker [114]; this may be related to a lack of storage space.

- Convenience can have many facets depending on the EA. For example, in relation to recycling, Brook Lyndhurst [66] reported that convenience is related to kerbside recycling service provision, distance from bring banks and their location in terms of everyday trips, availability of a car, and also issues of time and storage space. McDonald and Oates [115] drew a parallel between the concept of convenience in relation to recycling and Peattie's [95] concept of compromise in relation to green consumerism. The aspects of compromise include paying a premium for a green product, sacrificing product performance for environmental benefits, and having to obtain goods from non-standard outlets. Indeed, products made from recycled materials are often perceived as expensive, unattractive and low quality [66].

- In terms of cost, environmentally friendly products are commonly assumed to be expensive [66,67]. As a specific example, McEachern and McClean [116] found that among those who had never purchased organic dairy products, the main deterrent was pricing constraints. However, as Holdsworth [67] noted, such assumptions are not necessarily based upon experience or accurate information, a point relevant to all perceptions relating to logistical factors. Nevertheless, price remains a significant barrier to the purchase of new technologies such as energy efficient fridges and electric cars [39].

In Ölander and Thørgersen's [80] original motivation-ability-opportunity-behaviour model, an individual's ability to participate in an EA incorporates both habit and knowledge for action. While habit is an important determinant of behaviour it has less relevance to relative interest. Therefore here, ability refers solely to knowledge for action.

Knowledge of behavioural responses to environmental problems and how to engage in such EAs has been termed "action-related knowledge" [117], "concrete knowledge" and "knowledge for action" [118]. Knowledge for action is a prerequisite to EA participation [41,92,119]. This issue is particularly pertinent in relation to recycling as people need to know what, how, where and when to recycle in order to participate properly [41,54]. Indeed, Hayward et al. [111] and Pocock et al. [53] identified a lack of knowledge for action as a reason for not recycling more. Furthermore, it may also be the case that individuals misguidedly believe that they have the requisite knowledge for action $[67,120]$.

Limited attention has been focused on the acquisition of knowledge for action and how it is transmitted through the household [121]. However, in relation to individuals, a number of studies have highlighted the passive nature of the acquisition of knowledge for action, e.g., through seeing recycling facilities, recycling scheme leaflets, the media, shops and supermarkets, and information passed on from friends and trusted others [33,84,122-125]. Steedman [125] focused on the acquisition of knowledge and described actively seeking out information on EAs as a "specialist concern" (p. 1) as only 19\% of 
consumers had sought out information on at least one topic and only $8 \%$ on five or more topics. However, Steedman [125] also reported an apparent strong positive relationship between seeking information and acting on it: "it appears that once individuals go looking, the information they find does appear to help them take steps to change their behaviour" (p. 15).

\subsection{Underlying Circumstances}

The determining factors discussed in the previous section are shaped by various underlying circumstances highlighted by the literature pertaining to behaviour change in a natural setting. This literature consists of a limited number of studies which have so far remained unlinked. The underlying circumstances include public debate on environmental issues, transformative experiences, formative experiences during childhood, socialisation in current household, turning points in life course, and change in contextual conditions.

The influence of the general public debate on environmental issues underpinning attempts to try and reduce personal environmental impact in every life was recognised by Åberg et al. [5] and Mårtensson and Pettersson [126]. Participants in Mårtensson and Pettersson's [126] Swedish life histories study highlighted that such public debate was not their only influence; rather it had reinforced environmental interest or allowed them to define their former behaviour in environmental terms. Indeed, environmental attitudes were commonly based on childhood experiences.

Maiteny [127] noted that many of his interviewees' underlying reasons for their environmental concern and attempts to change their lifestyle were not overtly environmental. While some experiences were formative as a child or student, others were "'one-off' transformative experiences that had quite sudden effects on those individual's awareness and priorities" (p. 301). Such experiences included serious and seemingly unexplained illness leading to questions about food safety and the environment, and witnessing first-hand the less wasteful ways other people live, e.g., in less developed countries.

Formative experiences during childhood refer to a number of influences:

- Older individuals' participation in EAs which conserve resources can be rooted in experiencing shortage and thrift through periods such as the Second World War [88,126,128].

- EA participation may be part of an individual's upbringing either as part of a value system which emphasises thrift or a value system that stresses environmental concern $[88,126,127,129]$.

- Mårtensson and Pettersson [126] also identified experience of food cultivation and an interest in nature and outdoor life as formative experiences during childhood.

Drawing on Ward's [130] commonly employed definition of consumer socialisation, socialisation with respect to EAs can be regarded as the acquisition of skills (practices), knowledge and attitudes relating to EA participation from another household member. Easterling et al. [131] raised the possibility that children's environmental concern and knowledge may act as a catalyst for family behaviour change. Indeed, Brook Lyndhurst [66], Ekström [132], Gentina and Muratore [16], Maddox et al. [133], Mårtensson and Pettersson [126] and Woollam et al. [134], present empirical evidence of children and teenagers influencing their parents with respect to EA participation primarily by taking related messages home from school. Such situations have been referred to as children resocialising the family [131], reverse socialisation [4] and ecological resocialisation [16]. However, Grønhøj and Thøgersen [4] noted 
that in terms of intergenerational influence, parent to child socialisation influence is the dominant direction, and along with Grønhøj and Thøgersen [13], presented evidence to demonstrate the significant influence of family socialisation on adolescents' orientation with respect to EAs. This links with the point made in the "maintenance of repetitive environmental actions" section regarding the role of socialisation influence from parent to child in shaping routine and habitual behaviour and thus determining what is seen as normal practice. A third type of socialisation influence is from adult to adult as recognised by Grønhøj [9] and Grønhøj and Ölander [11] and mentioned in the "household member involvement in environmental adoption and practice" section.

Implicit in Easterling, Miller, and Weinberger [131], Grønhøj [9] and Grønhøj and Ölander's [11] discussion of socialisation influence is a change in behaviour and attitudes. However, behaviour change does not necessarily require attitude change [135]. Indeed, socialisation agents may be able to force other household members to practice EAs, and thus it is pertinent to distinguish between socialisation influence in terms of behaviour only and socialisation influence which results in the volitional practice of EAs [4]. Beyond identifying the types of socialisation influence within households, attention has begun to be paid to the mechanisms involved. For example, Grønhøj and Thøgersen [4] identified that it is actual parental behaviour (as opposed to attitudes) that is more influential in terms of adolescents' behaviour, and, as discussed in the "decision making strategies" section, Gentina and Muratore [16] explored the influence strategies used by teenagers in "reverse socialisation" and looked at the effect of parental style and frequency of communication.

EA adoption may be associated with turning points in individuals' life courses or moments of change such as leaving home, having a first child, moving house, and retiring [136]. For example, Carey, Shaw, and Shiu [14], Brook Lyndhurst [66] and Mårtensson and Pettersson [126] identified having children and moving into a family home as events which were associated with more regular domestic routines and encouraged individuals to think about the future, thus prompting increased engagement in recycling and other EAs. Conversely, having children or a time-consuming job may impede engagement in EAs due to limited time available or the need for increased car travel [129]. Schäfer et al. [137] identified that everyday routines change during life events, but that this may have heterogeneous effects on EAs; for example, childbirth may facilitate more sustainable transport behaviours as everyday life becomes more tied to the home and local area, but energy saving behaviours may be deprioritised in an effort to create a warm, clean and convenient family environment. The final underlying circumstance is change in contextual conditions of which the primary example is access to a kerbside recycling collection service. For example, in Brook Lyndhurst's [66] qualitative investigation, access to such as a service was the only reason why many people recycled. Brook Lyndhurst [66] also reported that for some High recyclers, participating in kerbside collections had raised their overall interest in recycling. Indeed, Werner et al. [138] presented evidence to suggest that participation in kerbside recycling led to changes in attitude. In other words, if a change in behaviour can be secured without accompanying change in attitudes, then over time, attitude change may occur.

\section{Conclusions and Future Directions}

The field of research into EA participation has produced a voluminous literature with a corresponding understanding of the factors/relationships between factors which influence behaviour and also an 
understanding of how to most effectively bring about voluntary behaviour change. However, by taking the individual as the unit of analysis, such work has typically ignored the relevance of the social context of the household to the adoption and practice of EAs. A growing number of studies have begun to take the household as the unit of analysis and have highlighted issues such as a link between gender, the domestic division of labour and involvement in EA adoption and practice [5,9-11,15,17,21,22], patterns of communication within the household regarding EAs $[9,11,16]$, and parent to child, child to parent and adult to adult socialisation influences [3-5,8-16]. However, the household perspective on EA participation remains under-researched.

We have brought together the largely unlinked work which has examined EA participation from the household perspective and integrated it with the household decision making literature, and the literature which has examined EA participation from the individual perspective, specifically the literature relating to the determinants of behaviour and the limited and fragmented work which has examined behaviour change in a natural setting. The result is a conceptual framework of the adoption and practice of lone EAs in households (Figure 1), which also offers some insights into patterns of adoption and practice across EA repertoires. Thus, we make an important theoretical contribution by presenting a conceptual rendering which represents a holistic understanding of EA participation from the household perspective, which was previously absent from the literature. It is important to note that given the relative paucity of work which has squarely investigated EA participation from the household perspective and the scant application of the HDM literature to such research, there are a number of elements of the conceptual framework that require further empirical investigation in order to advance the framework:

- The applicability of the spectrum of involvement in EA adoption from one individual being responsible for EA adoption in a specialised role through to all individuals being responsible in a shared role in relation to different EAs requires exploration. The same can be said for the spectrum of involvement in EA practice, particularly with respect to recycling, and the spectrum of general responsibility for EA adoption and practice across the EA repertoire including the relevance of the concept of the household EA officer.

- Further to the applicability of these spectrums of involvement is the identification of the detailed nature of these different involvement distributions. Inherent in this is examination of the applicability of the framework of relative influence across the decision making process and the nature of the decision making process itself in relation to EA adoption.

- Given that the explanation of role structure has greater theoretical value than simply identifying role structure [76,139], how activity types, individual characteristics, situational characteristics, and household characteristics influence household member involvement in EA adoption and practice, and how such factors are shaped and influence each other, warrants greater attention.

- Following on from a more detailed understanding of the different distributions of involvement in EA adoption and practice, is a more detailed understanding of the different routes to EA practice (i.e., the combinations of a particular distribution of involvement in EA adoption associated and a particular distribution of involvement in EA practice). This leads to the question of whether particular routes to EA practice produce greater environmental benefits. 
- Examination of the applicability of the framework of decision making strategies within a wider exploration of conflict-ridden and peaceful interpersonal influence processes, particularly the nature and mechanisms of socialisation influence from one household member to another.

- Investigation of how repetitive EAs are maintained in households, particularly with respect to the incorporation of such EAs into domestic routines and the role of self-organisation strategies in the maintenance of recycling, and how habitual behaviour is changed within the household.

- From where and how knowledge for action is sourced and how knowledge for action is transmitted through the household [121].

- The call for an examination of communication within the household with respect to EAs [121] is a cross-cutting issue but has particular relevance to the mechanisms of socialisation influence and the transmission of knowledge for action.

By identifying these avenues for exploration, we have also set out a clear agenda for empirical research into EA participation from a household perspective. Such research will allow the conceptual framework to be developed further, and contribute towards a more thorough understanding of the social context of the household for the benefit of more effective behaviour change and green marketing strategies.

\section{Acknowledgments}

The authors are grateful to the White Rose University Consortium for funding the research.

\section{Author Contributions}

Anna Scott 50\% (conducted data collection and analysis, led paper writing), Caroline Oates 25\% (contributed to research design, data collection and paper writing) and William Young 25\% (contributed to research design, data analysis and paper writing).

\section{Conflicts of Interest}

The authors declare no conflict of interest.

\section{References}

1. World Wildlife Fund (WWF); Zoological Society of London; Global Footprint Network; European Space Agency. Living Planet Report 2012: Biodiversity, Biocapacity and Better Choices; WWF: Gland, Switzerland, 2012.

2. Stern, P. Toward a coherent theory of environmentally significant behavior. J. Soc. Issues $\mathbf{2 0 0 0 ,}$ 56, 407-424.

3. Shanahan, H. Exploring everyday life in households for a sustainable society. In Proceedings of the 6th Nordic Conference on Environmental Social Sciences, Turku/Åbo, Finland, 12-14 June 2003.

4. Grønhøj, A.; Thøgersen, J. Action speaks louder than words: The effect of personal attitudes and family norms on adolescents' pro-environmental behaviour. J. Econ. Psychol. 2012, 33, 292-302.

5. Åberg, H.; Dahlman, S.; Shanahan, H.; Säljö, R. Towards sound environmental behaviour: Exploring household participation in waste management. J. Consum. Policy 1996, 19, 45-67. 
6. Shove, E. Comfort, Cleanliness and Convenience: The Social Organization of Normality; Berg Publishing: London, UK, 2003.

7. Shove, E. Efficiency and consumption: Technology and practice. In The earthscan Reader in Sustainable Consumption; Jackson, T., Ed.; Earthscan: London, UK, 2006; pp. 293-304.

8. Judkins, B.B. Families Practicing Sustainability: The Adoption and Maintenance of Environmentally Responsible Behaviors in the Context of Family Life. Ph.D. Thesis, University of Tennessee, Knoxville, UT, USA, 2004.

9. Grønhøj, A. Communication about consumption: A family process perspective on 'green' consumer practices. J. Consum. Behav. 2006, 5, 491-503.

10. Carlsson-Kanyama, A.; Lindén, A.-L. Energy efficiency in residences-Challenges for women and men in the north. Energy Policy 2007, 35, 2163-2172.

11. Grønhøj, A.; Ölander, F. A gender perspective on environmentally related family consumption. J. Consum. Behav. 2007, 6, 218-235.

12. Grønhøj, A.; Thøgersen, J. Feedback on household electricity consumption: Learning and social influence processes. Int. J. Consum. Stud. 2011, 35, 138-145.

13. Grønhøj, A.; Thøgersen, J. Like father, like son? Intergenerational transmission of values, attitudes, and behaviours in the environmental domain. J. Environ. Psychol. 2009, 29, 414-421.

14. Carey, L.; Shaw, D.; Shiu, E. The impact of ethical concerns on family consumer decision-making. Int. J. Consum. Stud. 2008, 32, 553-560.

15. Oates, C.J.; McDonald, S. Recycling and the domestic division of labour: Is green pink or blue? Sociology 2006, 40, 417-433.

16. Gentina, E.; Muratore, I. Environmentalism at home: The process of ecological resocialization by teenagers. J. Consum. Behav. 2012, 11, 162-169.

17. Pettifor, H. Patterns of Household Practice: An Examination into the Relationship between Housework and Waste Separation for Households in the United Kingdom; Iser Working Paper Series; Institute for Social and Economic Research, University of Essex: Colchester, UK, 2012.

18. Ewing, G. Altruistic, egoistic, and normative effects on curbside recycling. Environ. Behav. 2001, 33, 733-764.

19. Kok, G.; Siero, S. Tin recycling: Awareness, comprehension, attitude, intention and behavior. J. Econ. Psychol. 1985, 6, 157-173.

20. Reid, L.; Sutton, P.; Hunter, C. Theorizing the meso level: The household as a crucible of pro-environmental behaviour. Prog. Hum. Geogr. 2010, 34, 309-327.

21. Dickinson, W.H. Gender, household responsibility, and environmental behaviour. In Proceedings of the Association of American Geographers 90th Annual Meeting, San Francisco, CA, USA, 29 March-2 April 1994.

22. Díaz Meneses, G.; Beerli Palacio, A. Recycling behavior: A multidimensional approach. Environ. Behav. 2005, 37, 837-860.

23. Lee, C.K.-C. A model of family buyer behaviour. N. Z. J. Bus. 1992, 14, 50-60.

24. Levy, D.S.; Lee, C.K.-C. The influence of family members on housing purchase decisions. J. Prop. Invest. Financ. 2004, 22, 320-338.

25. Beatty, S.E.; Talpade, S. Adolescent influence in family decision making: A replication with extension. J. Consum. Res. 1994, 21, 332-341. 
26. Rossiter, J.R. Children's consumer research: A call for rigor. In Advances in Consumer Research Volume 6; Wilkie, W.L., Ed.; Association for Consumer Research: Ann Abor, MI, USA, 1979; pp. 424-426.

27. Belch, G.E.; Belch, M.A.; Ceresino, G. Parental and teenage child influences in family decision making. J. Bus. Res. 1985, 13, 163-176.

28. Belch, M.A.; Willis, L.A. Family decision at the turn of the century: Has the changing structure of households impacted the family decision-making process? J. Consum. Behav. 2002, 2, 111-124.

29. Martínez, E.; Polo, Y. Determining factors in family purchasing behaviour: An empirical investigation. J. Consum. Mark. 1999, 16, 461-481.

30. Kirchler, E.; Rodler, C.; Hölzl, E.; Meier, K. Conflict and Decision-Making in Close Relationships: Love, Money and Daily Routines; Psychology Press: Hove, UK, 2001.

31. Harrison, C.M.; Burgess, J.; Filius, P. Rationalizing environmental responsibilities: A comparison of lay publics in the uk and the netherlands. Glob. Environ. Chang. 1996, 6, 215-234.

32. Martin, M.; Williams, I.D.; Clark, M. Social, cultural and structural influences on household waste recycling: A case study. Resour. Conserv. Recycl. 2006, 48, 357-395.

33. McDonald, S.; Ball, R. Public participation in plastics recycling schemes. Resour. Conserv. Recycl. 1998, 22, 123-141.

34. Hormuth, S.E.; Katzenstein, H.; Bruch, B.; Ringenberger, B. Psychological studies on garbage avoidance and recycling. In EDRA 22: Healthy Environments; Urbina-Soria, J., Ortega-Andeane, P., Bechtel, R., Eds.; Environmental Design Research Association: Oklahoma City, OK, USA, 1991; pp. 321-325.

35. Thørgersen, J.; Grønhøj, A. Electricity saving in households-A social cognitive approach. Energy Policy 2010, 38, 7732-7743.

36. Davis, H.L.; Rigaux, B.P. Perception of marital roles in decision processes. J. Consum. Res. 1974, $1,51-62$.

37. Olshavsky, R.W.; Granbois, D.H. Consumer decision making-Fact or fiction? J. Consum. Res. 1979, 6, 93-100.

38. Oates, C.; McDonald, S.; Alevizou, P.; Hwang, K.; Young, W.; McMorland, L.-A. Marketing sustainability: Use of information sources and degrees of voluntary simplicity. J. Mark. Commun. 2008, 14, 351-365.

39. Young, W.; Hwang, K.; McDonald, S.; Oates, C.J. Sustainable consumption: Green consumer behaviour when purchasing products. Sustain. Dev. 2010, 18, 20-31.

40. Thøgersen, J.; Jørgensen, A.-K.; Sandager, S. Consumer decision making regarding a "green" everyday product. Psychol. Mark. 2012, 29, 187-197.

41. Pieters, R.G.M. Changing garbage disposal patterns of consumers: Motivation, ability, and performance. J. Public Policy Mark. 1991, 10, 59-76.

42. Lee, C.K.-C.; Collins, B.A. Family decision making and coalition patterns. Eur. J. Mark. 2000, 34, 1181-1198.

43. Wilkie, W.L.; Moore-Shay, E.S.; Assar, A. Family Decision-Making for Household Durable Goods; Marketing Science Institute Working Paper Report Number 92-108; Marketing Science Institute: Cambridge, MA, USA, 1992. 
44. Nelson, M.C. The resolution of conflict in joint purchase decisions by husbands and wives: A review and empirical test. In Advances in Consumer Research Volume 15; Houston, M.J., Ed.; Association for Consumer Research: Provo, UT, USA, 1988; pp. 436-441.

45. Davis, H.L. Decision making within the household. J. Consum. Res. 1976, 2, 241-260.

46. Qualls, W.J.; Jaffe, F. Measuring conflict in household decision behavior: Read my lips and read my mind. In Advances in Consumer Research Volume 19; Sherry, J.F., Sternthal, B., Eds.; Association for Consumer Research: Provo, UT, USA, 1992; pp. 522-531.

47. Sheth, J.N. A theory of family buying decisions. In Models of Buyer Behavior: Conceptual, Quantitative, and Empirical; Sheth, J.N., Ed.; Harper and Row: New York, NY, USA, 1974; pp. 17-33.

48. Spiro, R.L. Persuasion in family decision-making. J. Consum. Res. 1983, 9, 393-402.

49. Carlson, L.; Grossbart, S. Parental style and consumer socialization of children. J. Consum. Res. 1988, 15, 77-94.

50. Reid, L.; Hunter, C.; Sutton, P.W. Rising to the challenge of environmental behaviour change: Developing a reflexive diary approach. Geoforum 2011, 42, 720-730.

51. Tucker, P.; Speirs, D. Attitudes and behavioural change in household waste management behaviours. J. Environ. Plan. Manag. 2003, 46, 289-307.

52. Oates, C.J.; McDonald, S. What can marketing do for recycling? In Proceedings of the Academy of Marketing, Nottingham, UK, 4-6 July 2002.

53. Pocock, R.; Stone, I.; Clive, H.; Smith, R.; Jesson, J.; Wilczak, S. Barriers to Recycling at Home; Waste and Resources Action Programme: Banbury, UK, 2008.

54. Hansmann, R.; Bernasconi, P.; Smieszek, T.; Loukopoulos, P.; Scholz, R.W. Justifications and self-organization as determinants of recycling behavior: The case of used batteries. Resour. Conserv. Recycl. 2006, 47, 133-159.

55. Werner, C.M.; Makela, E. Motivations and behaviors that support recycling. J. Environ. Psychol. 1998, 18, 373-386.

56. Burgess, J. Sustainable consumption: Is it really achievable? Consum. Policy Rev. 2003, 13, $78-84$.

57. Lewin, K. Group decision and social change. In Readings in Social Psychology; Maccoby, E.E., Newcomb, T.M., Hartley, E.L., Eds.; Holt, Rinehart and Winston: New York, NY, USA, 1958.

58. Dahlstrand, U.; Biel, A. Pro-environmental habits: Propensity levels in behavioral change. J. Appl. Soc. Psychol. 1997, 27, 588-601.

59. Hobson, K. Thinking habits into action: The role of knowledge and process in questioning household consumption practices. Local Environ. 2003, 8, 95-112.

60. Jackson, T. Motivating Sustainable Consumption: A Review of Evidence on Consumer Behaviour and Behavioural Change; University of Surrey: Guildford, UK, 2005.

61. Staats, H.; Harland, P.; Wilke, H.A.M. Effecting durable change: A team approach to improve environmental behavior in the household. Environ. Behav. 2004, 36, 341-367.

62. Global Action Plan. Changing Environmental Behaviour: A Review of Evidence from Global Action Plan; Global Action Plan: London, UK, 2006.

63. Gupta, S.; Hagerty, M.R.; Myers, J.G. New directions in family decision making research. In Advances in Consumer Research Volume 10; Bagozzi, R.P., Tybout, A.M., Eds.; Association for Consumer Research: Ann Abor, MI, USA, 1983; pp. 445-450. 
64. Gilg, A.; Barr, S. Encouraging 'environmental action' by exhortation: Evidence from a study in devon. J. Environ. Plan. Manag. 2005, 48, 593-618.

65. Defra. A Framework for Pro-Environmental Behaviours; Department for Environment, Food and Rural Affairs: London, UK, 2008.

66. Lyndhurst, B. Household Waste Behaviour in London Phase 2: High, Medium and Low Recyclers: Attitudes, Behaviour and Needs; Resource Recovery Forum: Skipton, UK, 2004.

67. Holdsworth, M. Green Choice: What Choice? Summary of Ncc Research into Consumer Attitudes to Sustainable Consumption; National Consumer Council: London, UK, 2003.

68. Qualls, W.J. Household decision behavior: The impact of husbands' and wives' sex role orientation. J. Consum. Res. 1987, 14, 264-279.

69. Ferber, R.; Lee, C.L. Husband-wife influence in family purchasing behavior. J. Consum. Res. 1974, $1,43-50$.

70. Blackwell, R.D.; Miniard, P.W.; Engel, J.F. Consumer Behavior, 9th ed.; Harcourt College Publishers: Fort Worth, TX, USA, 2001.

71. Burns, A.C.; Granbois, D.H. Factors moderating the resolution of preference conflict in family automobile purchasing. J. Mark. Res. 1977, 14, 77-86.

72. Gregory, G.D.; di Leo, M. Repeated behavior and environmental psychology: The role of personal involvement and habit formation in explaining water consumption. J. Appl. Soc. Psychol. 2003, $33,1261-1296$.

73. Fitzmaurice, J. Incorporating consumers' motivations into the theory of reasoned action. Psychol. Mark. 2005, 22, 911-929.

74. Corfman, K.P.; Lehmann, D.R. Models of cooperative group decision-making and relative influence: An experimental investigation of family purchase decisions. J. Consum. Res. 1987, 14, $1-13$.

75. Burns, A.C. Spousal involvement and empathy in jointly-resolved and authoritatively-resolved purchase subdecisions. In Advances in Consumer Research Volume 3; Anderson, B.B., Ed.; Association for Consumer Research: Cincinnati, OH, USA, 1976; pp. 199-207.

76. Morgan, J.N. Household decision-making. In Household Decision-Making; Foote, N.N., Ed.; New York University Press: New York, NY, USA, 1961; Volume IV, pp. 81-102.

77. Barr, S. Household Waste in Social Perspective: Values, Attitudes, Situation and Behaviour; Ashgate: Aldershot, UK, 2002.

78. Kollmuss, A.; Agyeman, J. Mind the gap: Why do people act environmentally and what are the barriers to pro-environmental behavior? Environ. Educ. Res. 2002, 8, 239-260.

79. Darnton, A.; Elster-Jones, J.; Lucas, K.; Brooks, M. Promoting Pro-Environmental Behaviour: Existing Evidence to Inform Better Policy Making: Summary Report; Centre for Sustainable Development, University of Westminster: London, UK, 2006.

80. Ölander, F.; Thørgersen, J. Understanding of consumer behaviour as a prerequisite for environmental protection. J. Consum. Policy 1995, 18, 345-385.

81. Fishbein, M.; Ajzen, I. Belief, Attitude, Intention and Behavior: An Introduction to Theory and Research; Addison-Wesley: Boston, MA, USA, 1975.

82. Schwartz, S.H. Normative influences on altruism. Adv. Exp. Soc. Psychol. 1977, 10, 221-279. 
83. Bagozzi, R.P.; Dabholkar, P.A. Consumer recycling goals and their effect on decisions to recycle: A means-end chain analysis. Psychol. Mark. 1994, 11, 313-340.

84. Brook, L. Public Understanding of Sustainable Energy Consumption in the Home: A Research Report Completed for the Department for Environment, Food and Rural Affairs by Brook Lyndhurst; Department for Environment, Food and Rural Affairs: London, UK, 2007.

85. Defra. Survey of Public Attitudes to Quality of Life and to the Environment-2001; Department for Environment, Food and Rural Affairs: London, UK, 2002.

86. De Young, R. New ways to promote proenvironmental behavior: Expanding and evaluating motives for environmentally responsible behavior. J. Soc. Issues 2000, 56, 509-526.

87. Davies, J.; Foxall, G.R.; Pallister, J. Beyond the intention-behaviour mythology: An integrated model of recycling. Mark. Theory 2002, 2, 29-113.

88. Hallin, P.O. Environmental concern and environmental behavior in foley, a small town in minnesota. Environ. Behav. 1995, 27, 558-578.

89. Hunecke, M.; Blöbaum, A.; Matthies, E.; Höger, R. Responsibility and environment: Ecological norm orientation and external factors in the domain of travel mode choice behavior. Environ. Behav. 2001, 33, 830-852.

90. Kaiser, F.G.; Hübner, G.; Bogner, F.X. Contrasting the theory of planned behavior with the value-belief-norm model in explaining conservation behavior. J. Appl. Soc. Psychol. 2005, 35, 2150-2170.

91. Darnton, A. Driving Public Behaviours for Sustainable Lifestyles: Report 2 of Desk Research commissioned by COI on behalf of Defra. Available online: http://collections.europarchive.org/ tna/20080530153425/http://www.sustainable-development.gov.uk/publications/pdf/deskresearch2.pdf (accessed on 8 May 2015).

92. Hines, J.M.; Hungerford, H.R.; Tomera, A.N. Analysis and synthesis of research on responsible environmental behavior: A meta analysis. J. Environ. Educ. 1987, 18, 1-8.

93. Berger, I.E.; Corbin, R.M. Perceived consumer effectiveness and faith in others as moderators of environmentally responsible behaviors. J. Public Policy Mark. 1992, 11, 79-89.

94. Straughan, R.D.; Roberts, J.A. Environmental segmentation alternatives: A look at green consumer behavior in the new millennium. J. Consum. Mark. 1999, 16, 558-575.

95. Peattie, K. Golden goose or wild goose? The hunt for the green consumer. Bus. Strateg. Environ. 2001, 10, 187-199.

96. Roberts, J.A. Green consumers in the 1990s: Profile and implications for advertising. J. Bus. Res. 1996, 36, 217-231.

97. Lee, J.A.; Holden, S.J.S. Understanding the determinants of environmentally conscious behavior. Psychol. Mark. 1999, 16, 373-392.

98. Ajzen, I. The theory of planned behavior. Organ. Behav. Hum. Decis. Process. 1991, 50, 179-211.

99. Cialdini, R.B.; Reno, R.R.; Kallgren, C.A. A focus theory of normative conduct: Recycling the concept of norms to reduce littering in public places. J. Person. Soc. Psychol. 1990, 58, 1015-1026.

100. Oskamp, S.; Harrington, M.J.; Edwards, T.C.; Sherwood, D.L.; Okuda, S.M.; Swanson, D.C. Factors influencing household recycling behaviour. Environ. Behav. 1991, 23, 494-519. 
101. Gamba, R.J.; Oskamp, S. Factors influencing community residents' participation in commingled curbside recycling programs. Environ. Behav. 1994, 26, 587-612.

102. Berger, I.E. The demographics of recycling and the structure of environmental behavior. Environ. Behav. 1997, 29, 515-531.

103. Best, H.; Kneip, T. The impact of attitudes and behavioral costs on environmental behavior: A natural experiment on household waste recycling. Soc. Sci. Res. 2011, 40, 917-930.

104. Derksen, L.; Gartrell, J. The social context of recycling. Am. Sociol. Rev. 1993, 58, 434-442.

105. Diekmann, A.; Preisendörfer, P. Green and greenback: The behavioral effects of environmental attitudes in low-cost and high-cost situations. Ration. Soc. 2003, 15, 441-472.

106. Guagnano, G.A.; Stern, P.C.; Dietz, T. Influences on attitude-behavior relationships: A natural experiment with curbside recycling. Environ. Behav. 1995, 27, 699-718.

107. Darnton, A. The Impact of Sustainable Development on Public Behaviour: Report 1 of Desk Research commissioned by COI on behalf of Defra. Available online: http://collections. europarchive.org/tna/20080530153425/http://www.sustainable-development.gov.uk/publications/ pdf/desk-research1.pdf (accessed on 8 May 2015).

108. Robinson, G.M.; Read, A.D. Recycling behaviour in a london borough: Results from large-scale household surveys. Resour. Conserv. Recycl. 2005, 45, 70-83.

109. Watts, B.M.; Probert, E.J. Variation in public participation in recycling: A case study in swansea. Environ. Waste Manag. 1999, 2, 99-106.

110. ENCAMS. Waste Segmentation Research 2002; ENCAMS: Wigan, UK, 2002.

111. Hayward, B.; Turtle, J.; Carpenter, H.; Hanson, T. Attitudes and Behaviour in Relation to the Environment; Department for Environment, Food and Rural Affairs: London, UK, 2007.

112. McDonald, S.; Oates, C. Reasons for non-participation in a kerbside recycling scheme. Resour. Conserv. Recycl. 2003, 39, 369-385.

113. Perrin, D.; Barton, J. Issues associated with transforming household attitudes and opinions into materials recovery: A review of two kerbside recycling schemes. Resour. Conserv. Recycl. 2001, 33, 61-74.

114. Tucker, P. A survey of attitudes and barriers to kerbside recycling. Environ. Waste Manag. 1999, 2, 55-62.

115. McDonald, S.; Oates, C.J. Sustainability: Consumer perceptions and marketing strategies. Bus. Strateg. Environ. 2006, 15, 157-170.

116. McEachern, M.G.; McClean, P. Organic purchasing motivations and attitudes: Are they ethical? Int. J. Consum. Stud. 2002, 26, 85-92.

117. Frick, J.; Kaiser, F.G.; Wilson, M. Environmental knowledge and conservation behavior: Exploring prevalence and structure in a representative sample. Person. Individ. Differ. 2004, 37, 1597-1613.

118. Schahn, J.; Holzer, E. Studies of individual environmental concern: The role of knowledge, gender and background variables. Environ. Behav. 1990, 22, 767-786.

119. Barr, S. Factors influencing environmental attitudes and behaviors: A u.K. Case study of household waste management. Environ. Behav. 2007, 39, 435-473.

120. Ellen, P.S. Do we know what we need to know? Objective and subjective knowledge effects on pro-ecological behaviors. J. Bus. Res. 1994, 30, 43-52. 
121. Pennartz, P.; Niehof, A. The Domestic Domain: Chances, Choices and Strategies of Family Households; Ashgate: Aldershot, UK, 1999.

122. Ball, R.; Lawson, S.M. Public attitudes towards glass recycling in scotland. Waste Manag. Res. 1990, 8, 177-192.

123. Belton, V.; Crowe, D.V.; Matthews, R.; Scott, S. A survey of public attitudes to recycling in glasgow (U.K.). Waste Manag. Res. 1994, 12, 351-367.

124. Vining, J.; Ebreo, A. What makes a recycler? A comparison of recyclers and nonrecyclers. Environ. Behav. 1990, 22, 55-73.

125. Steedman, P. Desperately Seeking Sustainability? Summary of Ncc Research into Information and Advice on Sustainable Lifestyles; National Consumer Council: London, UK, 2005.

126. Mårtensson, M.; Pettersson, R. Everyday life contexts and the environment. In Individual and Structural Determinants of Environmental Practice; Biel, A., Hansson, B., Mårtensson, M., Eds.; Ashgate: Aldershot, UK, 2003; pp. 26-65.

127. Maiteny, P.T. Mind in the gap: Summary of research exploring 'inner' influences on pro-sustainability learning and behaviour. Environ. Educ. Res. 2002, 8, 299-306.

128. Carlsson-Kanyama, A.; Lindén, A.-L.; Eriksson, B. Residential energy behaviour: Does generation matter? Int. J. Consum. Stud. 2005, 29, 239-253.

129. Hards, S. Changing Live to Tackle Climate Change: Why Do People Adopt and Maintain Sustainable Lifestyles? University of York: York, UK, 2012.

130. Ward, S. Consumer socialization. J. Consum. Res. 1974, 1, 1-14.

131. Easterling, D.; Miller, S.; Weinberger, N. Environmental consumerism: A process of children's socialization and families' resocialization. Psychol. Mark. 1995, 12, 531-550.

132. Ekström, K.M. Parental consumer learning or 'keeping up with the children'. J. Consum. Behav. 2007, 6, 203-217.

133. Maddox, P.; Doran, C.; Williams, I.D.; Kus, M. The role of intergenerational influence in waste education programmes: The thaw project. Waste Manag. 2011, 31, 2590-2600.

134. Woollam, T.; Griffiths, A.; Williams, K. Do children take the recycling message home from school? In Proceedings of the 21st Solid Waste Technology and Management Conference, Philadelphia, PA, USA, 26-29 March 2006.

135. Uzzell, D.; Muckle, R.; Jackson, T.; Ogden, J.; Barnett, J.; Gatersleben, B.; Hegarty, P.; Papathanasopoulou, E. Choice Matters: Alternative Approaches to Encourage Sustainable Consumption and Production; Environmental Psychology Research Group, University of Surrey: Guildford, UK, 2006.

136. Thompson, S.; Michaelson, J.; Abdallah, S.; Johnson, V.; Morris, D.; Riley, K.; Simms, A. Moments of Change as Opportunities for Influencing Behaviour: A Report to the Department for Environment, Food and Rural Affairs by Nef (the New Economics Foundation); Department for Environment, Food and Rural Affairs: London, UK, 2011.

137. Schäfer, M.; Jaeger-Erben, M.; Bamberg, S. Life events as windows of opportunity for changing towards sustainable consumption patterns? J. Consum. Policy 2012, 35, 65-84.

138. Werner, C.M.; Turner, J.; Shipman, K.; Twitchell, F.S.; Dickson, B.R.; Bruschke, G.V.; von Bismarck, W.B. Commitment, behavior, and attitude change: An analysis of voluntary recycling. J. Environ. Psychol. 1995, 15, 197-208. 
139. Lackman, C.; Lanasa, J.M. Family decision-making: An overview and assessment. Psychol. Mark. 1993, 10, 81-93.

(C) 2015 by the authors; licensee MDPI, Basel, Switzerland. This article is an open access article distributed under the terms and conditions of the Creative Commons Attribution license (http://creativecommons.org/licenses/by/4.0/). 